EDITORIAL

\title{
Initiatives and Pitfalls in Medical Care and E ducation in a Digital Age
}

\author{
A bul Kalam Azad \\ Directorate General of Health Services, M ohakhali, D haka
}

With adoption of digital technology in the medical colleges of Bangladesh is a feeling of frustration among some. These organizations have professionals of the highest level with medical degree and have also the best available environment and resources among the health facilities in Bangladesh. Y et, eH ealth progress is the slowest in these organizations. Except few most modernized private hospitals, the same remarks may go also for medical colleges in the private sector of the country.

Why this kind of situation has been created? Let me explain. In December 2012, World Health Organization's mHealth Technical Advisory Group termed Bangladesh's speed of $\mathrm{mH}$ ealth or eH eal th implementation as a bullet train. In fact, there is no second example in the developing world, which achieved so much progress in a short span of time. Bangladesh received the United Nations "Digital Health for Digital Development A ward", which is well-known as the "South-South Award". This award was received for our achievement in eH ealth. The world now wants to listen about our success.

So, we understand -- Bangladesh has made some definite progress in the use of digital technology in the health sector, and this is well-recognized in the world. This development has been taken place in the health delivery chain of the government -- in hospitals and grass roots levels in M inistry, DG-Health, Divisions, Districts, U pazilas and villages.

We have distributed 3,500 laptops and modems to community clinics. We have procured laptops for all other community clinics (total 18,000). We also bought 3,500 iPAD-like tablet handheld devices for the community

Bangladesh J M ed Biochem 2013; 6(2): 37-39 health workers. By next 2 years all the 25,000 to 30,000 community health workers will have an Internet connected handheld device.

Currently we collect health service data from around 1,000 organizations online in a central cloud server system using an internationally well-reputed software called District Health Information System (DHIS), which can automatically analyze data and produce automatic summary tables, charts and GIS maps. W e operate mobile phone health service from all district and upazila hospitals, use video conferencing system for meetings and telemedicine. In 800 hospitals and health offices, we have signboards on the walls to demonstrate to clients how to send their complaints or suggestions if they are not satisfied with the service. These are innovative. Each day we receive many complaints, we call the senders to understand better why they are not satisfied. There are wide range of complaints, ranging from unclean toilet, doctor's absenteeism to corruption and misbehavior. Then we talk with the local health authority and help to improve the situation. This is the third eye -- the citizens' eye, through which we see all government hospitals -- without physically visiting those hospitals. We are installing biometric finger print machines in all upazila and district hospitals to check staff attendance from Dhaka. The hand held devices with community health workers and laptops in the community clinics will also be used for tracking geo-locations and time stamp of attendance and also for educating local people as well as staffs through appropriate multi-media health contents. We are trying to automate human resource management system, like posting, transfer, leave management, etc. 
through digital means. Y ou are already aware how we conduct the large scale national medical and dental admission system in the country through using mobile phone and web based platforms.

Do we know that our digitally literate youth communities, who are studying or just entered jobs, do not read news papers, do not watch TV $s$ and do not listen to radio programs? They spend much of the time on Facebook, Twitter, Googlet, Y ouTube, Blogging, etc. Globally $20-30 \%$ of the young population has the same behavior according to a recent global report. Therefore, we have created Social Media Services in our official website.

On the contrary, there are frustrations about the medical colleges and postgraduate institutions. The faculties in these institutions, although have personnel having the highest level of professional degrees, in general, among all the professionals across the health sector, we did not find any remarkable initiative from among them who can give leadership (rather one may say ownership) to implement digital health program in the medical education setting of the country. Without local initiative, it is not possible for us to closely monitor implementation of projects in each academic institution. Sorry to say, our teachers in medical schools do not have enough free time to think and innovate. They are not taking advantage of modern technology to save precious time -- some are extremely are busy with private practice -- some are with own families --some kill valuable time with gossiping. This is the reality.

One may say where is computer? Where is Internet in these organizations? These are not major barriers. If we just carefully think and look, we would see that almost all of our students have a laptop or computer with Internet and email. They use Facebook. All of the teachers also have computers and/or laptops. They have Internet and email accounts. So, where is the problem? Some local institutional resources can easily be mobilized. First, we need to assess the requirement and what we al ready have. What is the gap? The minor gap is easy to fill up. Our teachers mostly use PowerPoint presentations. Some consult Internet for educational contents. Some use data analysis function. But, this is not digital. Digital means to take the full advantage of ICT within the available resources -- digital means to making yourself and your students as the members of global health community -- to make benefit from and to contribute to the whole world.

We need to discuss scope of digital libraries -very rich with world class contents. But, what about local contents? When we give lecture in the class, we certainly give examples on Bangladesh origin. Because these best suit our students to understand. Why not we record these lectures and put on the web site so that students from all medical schools benefit from them. If you make better plan, you can make even better lectures full of multimedia contents. Bright examples remain in Bangladesh. The secondary schools of Bangladesh started multi-media class room program -- very popular and very exciting. Teachers in Panchagarh or Satkhira are making creative multimedia learning materials and the entire country is using these contents.

Recently there was a report published by the Independent International Commission on M edical Education headed by Dr Lincon Chen, Chairman of China Medical Board with a member from Bangladesh -- Dr Tim Evans, Dean of James $P$ Grant School of Public $\mathrm{Health}$. The report titled "Medical Education for the 21st Century" urges for transformative medical education to produce change leaders -not wise men or specialists. The report also advises that the 21st century medical education will not remain confined to campus, rather the whole world and particularly the community where people live in, will be students' class room. Digital technology may help achieve this goal without requiring travel to the community. 
Initiatives and pitfalls in M edical Care and Education in Digital age

We have now Skype, with which one can now talk every day with your son or daughter, brother or sister staying abroad for higher education. The TV channels in Bangladesh are successfully using Skype to make available important persons to join in their talk shows from home. Suppose, you will teach your students -- Kala azar in class room. Kala azar is an endemic disease in Bangladesh caused by sand fly and people living in areas, where mud houses are the usual habitat, are mostly affected. Now we can request one of the teachers of a partner medical school near the endemic area to go to the Kala azar affected homes, set up a real time Skype connection to a class room and join with our students on real time conversation. O ur students can directly see the homes, the walls where sand flies live, other environmental conditions, can talk to family members or to a co-lecturer. Suppose, there is a modern machine in some other institution in your country or even in other country. If we want to show it to our students we may ask a teacher of such institution to give a demonstration to our students real time. We may help our students watch an ongoing surgery anywhere through video conference and ask to join in discussion with surgeons. We can demonstrate how a specialist can use video conference to guide a junior doctor give emergency treatment to an emergency patient in a remote location, if the patient is not in a condition to be transferred or the junior doctor does not know how to manage such condition.

Doctors in a remote rural facility can take an ECG or X-ray, scan it and send by email to specialists in urban settings. The specialists then will send the reports by email. Doctors can also take photo of a slide putting a digital camera on the objective of microscope and can send the photo to a pathologist, microbiologist or hematologist for report. Doctors sitting in urban area can see a patient sitting in a rural outreach and type prescription to be printed in the outreach center. In fact, we are already using some of these techniques in Bangladesh. Currently many low cost devices are available which can do common biochemical tests, do spirometry or can take ECG or measure pulse rate or blood pressure and can send from remote site to doctors. M edical calculators can do instant and quick estimation of body condition, dose calculation or alert for drug interactions in multiple therapy and therefore of great help in decision support for diagnosis and treatment.

Using digital technology can help making available medical care to the unreachable poor economic setting quickly, cheaply and easily. Our access to global knowledge and our quest for innovations will help find the solution.

During the Hippocrates era, the apprentices learned medicine working directly under the master. Five hundred years later, Galen discovered Anatomy and Physiology and established medical curriculum to teaching students fixed lessons. This system continued for subsequent 1500 years. Until 19th century, universities and schools made medical students learn by reading books and literatures. Then, Osler famously insisted that his students would learn at the bedside of patients. Later A braham Flexner identified large disparities between medical education standards across the North A merica and defined curriculum and needs that set the path of modern medicine. Today the medical education is paced by exponential increase of knowledge and technology. Students will have to assimilate more knowledge in less time, have to sacrifice obsolete knowledge and learn better from practical environment which was otherwise impossible earlier. We will therefore definitely and urgently welcome the adoption digital technology in medical education. We need not wait any more rather take a step and take it now . 